\title{
ARQUITETURA COM CHEIRO DE MATO: A EXPERIÊNCIA PARTICIPATIVA NA CONCEPÇÃO DE UM CENTRO COMUNITÁRIO
}

\section{AROUITETURA COM CHEIRO DE MATO: THE PARTICIPATORY EXPERIENCE IN THE DESIGN OFA COMMUNITY CENTER}

\section{Thiago de Carvalho Brito, M.Sc (UNP); Paulo José Nobre, Dr. (UFRN); Fernanda Lorena Rabelo de Oliveira (UNP)}

\author{
Palavras Chave \\ Arquitetura Bioclimática; Processo Participativo; Centro Comunitário
}

\author{
Key Words \\ Bioclimatic Architecture; Participatory Process; Community Center
}

\section{RESUMO}

O presente artigo está pautado na aplicação do processo participativo como metodologia de um projeto social, visando demonstrar a eficácia do diálogo com a comunidade na construção de um programa de necessidades condizente com a realidade local e que fortalece sentimentos de pertencimento e identidade com o lugar. Em consonância com esse objetivo, propõe-se um anteprojeto arquitetônico de um Centro Comunitário situado no bairro de Lagoa Azul no município de Natal/RN. Nesse contexto, foi adotado como conceito a "Arquitetura com Cheiro de Mato", que resgata a relação do homem com o meio ambiente e suas memórias afetivas vinculadas aos elementos naturais e utilizando os princípios da Arquitetura Bioclimática. As diretrizes do projeto foram definidas a partir do uso dos aspectos bioclimáticos e do processo participativo como condicionantes projetuais, desenvolvidos a partir de estudos teórico-metodológicos-referenciais que possibilitaram estabelecer relações entre esses temas. Espera-se que a adoção de tal percurso metodológico possa promover soluções mais adequadas ao lugar, gerando maior qualidade de vida e a preservação do meio ambiente.

\section{ABSTRACT}

This article is based on the application of the participatory process as a methodology of a social project, aiming to demonstrate the effectiveness of the dialogue with the community in the construction of a program of needs consistent with the local reality which also strengthens feelings of belonging and identity with the place. Consistent with this objective, an architectural conceptual-project is proposed for a Community Center located in the Lagoa Azul neighborhood in the city of Natal / RN. In this context, the concept "Arquitetura com Cheiro de Mato" was adopted, which rescues the relation of the man and the environment as well as the affective memories linked to natural elements by using the principles of Bioclimatic Architecture. The project guidelines were defined based on the use of bioclimatic aspects and the participatory process as design constraints, developed from theoretical-methodological-referential studies that enabled the establishment of relationships between these themes. It is hoped that the adoption of such a methodological course may promote solutions more appropriate to the place, generating a higher quality of life and better preservation of the environment. 


\section{INTRODUÇÃO}

Na segunda metade do século XX, o Brasil passou por um processo intenso e rápido de urbanização, transformando seu território, até então predominantemente rural, em urbano e metropolitano. Porém, essa mudança não se processou de forma harmoniosa e vem, ao longo do tempo, gerando um crescimento desordenado. Diante desse cenário, alguns instrumentos de controle do uso e ocupação do solo urbano têm sido usados como ferramentas importantes. Entretanto, mesmo com a existência dos condicionantes urbanísticos, como por exemplo, a necessidade de previsão de áreas destinadas à implantação de equipamentos urbanos e comunitários em loteamentos, os espaços livres públicos, por vezes, permanecem sem beneficiamentos e sem uma participação popular efetiva.

Para garantir maior inclusão e democracia na construção dos espaços públicos, a temática do "processo participativo" surge como uma alternativa para encarar a dimensão social e política nos projetos de interesse coletivo, ampliando a discussão para todos os segmentos da sociedade, de modo que possibilite a exposição da opinião e dos anseios dos usuários.

O artigo aqui apresentado faz parte da dissertação desenvolvida para o Programa de Pós-Graduação em Arquitetura, Projeto e Meio Ambiente do Departamento de Arquitetura da UFRN. Isso posto, o trabalho propõe um anteprojeto arquitetônico de um Centro Comunitário, com a finalidade de incentivar a participação da comunidade no processo projetual, o compartilhamento de experiências e conhecimentos entre os moradores e para atender as demandas de beneficiamento de uma produção de agricultura orgânica.

A área em estudo localiza-se no bairro de Lagoa Azul, situado no município de Natal-RN, onde se encontra a comunidade de Gramorezinho formada por pequenos produtores que desenvolvem a horticultura orgânica, representados pela associação "AMIGO VERDE", encarregada de beneficiar e comercializar a produção local (Figura 01).

Figura 01 - Área de produção agrícola de Gramorezinho

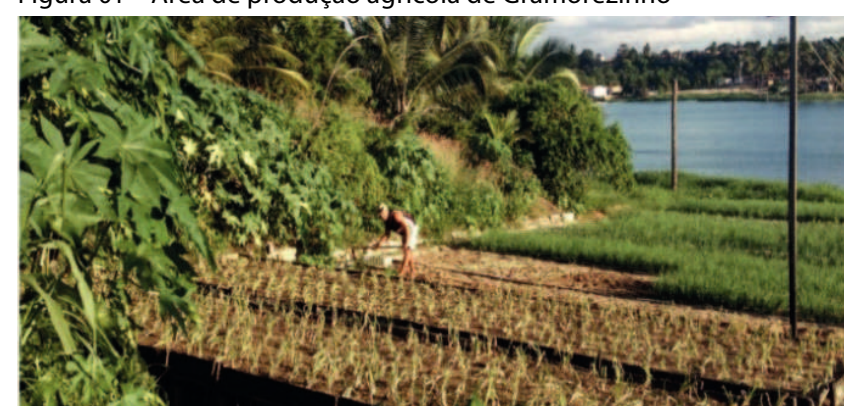

Fonte: Acervo do autor (2015).
O desenvolvimento da proposta buscou aplicar os princípios da arquitetura bioclimática, entendida como uma arquitetura integrada, que se adapta ao ambiente físico, socioeconômico e cultural. Além disso, utiliza materiais e técnicas autócnes e formas tradicionais, que reduzem o impacto ambiental.

Em geral, é uma arquitetura pensada com o clima do lugar, o sol, o vento, a vegetação e a topografia, com um desenho que permite tirar proveito das condições naturais do lugar, estabelecendo condições adequadas de conforto físico e mental dentro do espaço físico em que se desenvolve (CORREA, 2001, p. 01).

Embora o enfoque deste artigo seja no processo participativo, a aplicação dos princípios bioclimáticos possibilitou a construção de um programa de necessidades condizente com a realidade local, principalmente no que se refere ao uso de materiais e técnicas construtivas. Assim, foi estabelecido um percurso que fortaleceu as relações interpessoais e evidenciou o sentimento de pertencimento e identidade com o lugar.

\section{MÉTODOS E MATERIAIS APLICADOS NO PROCESSO PROJETUAL}

Entende-se que a participação coletiva na concepção do Centro Comunitário é importante porque esse espaço será destinado a uma associação já articulada e com um senso coletivo acentuado. Além disso, no momento em que a comunidade tem a oportunidade de expor a sua realidade, torna-se mais fácil o desenvolvimento do projeto arquitetônico e a sua leitura funcional, ou seja, os objetivos são alcançados de forma mais efetiva e as soluções são encontradas mais rapidamente. Nunes (2002) ressalta a importância das atividades pedagógicas, como forma de envolver a comunidade.

Nessas atividades, buscava-se, de início, estabelecer um contato entre os habitantes, mas um contato diferente daqueles de vizinhança, pois deveria permitir o relacionamento das pessoas na escala do bairro. Seu objetivo era fazer o habitante sair do seu quadro imediato - sua vida pessoal e familiar, seus vizinhos, sua rua - para reencontrar o bairro e os outros, os vizinhos desconhecidos. Essas primeiras atividades de intervenção foram importantes também para continuar a apresentação da equipe de animadores aos habitantes, o que havia começado com a aplicação dos questionários (NUNES, 2002, pg. 66).

Visando atingir os objetivos do projeto, principalmente inserir a comunidade no desenvolvimento do programa de necessidades, foi montada uma Oficina Participativa, para proporcionar uma visão mais abrangente sobre a qualidade técnica do projeto e para a promoção de debates acerca das 
necessidades, carências e dificuldades dos futuros usuários. Logo, entendendo que as atividades interativas auxiliam na compreensão e na facilitação do diálogo, optou-se pelo processo de exposição da proposta inspirado nas atividades definidas por Nunes (2002). Para tanto, foram desenvolvidos painéis interativos, com representações gráficas de fácil compreensão, próximas a realidade local e que permitissem o maior envolvimento possível dos participantes.

Para a atividade da Oficina Participativa destacam-se três etapas distintas: a programação, quando todo o roteiro foi planejado considerando a data e o local agendado para o evento, o tempo estimado, as ações pretendidas para as atividades e os responsáveis pela condução da ofinica; além de uma listagem dos materiais didaticos e dos equipamentos de infraestrutura local, para o pleno desenvolvimento da oficina participativa.

O segundo passo foi a elaboração do material, que contou com a participação de cinco (05) alunos voluntários do quinto $\left(5^{\circ}\right)$ período do curso de Arquitetura e Urbanismo da Universidade Potiguar (UNP) para ajudar na montagem, organização e execução da oficina. Inicialmente houve uma reunião de planejamento para refletir e organizar as atividades coletivamente, procurando visualizar todo o processo e elaborar, através de croquis, as ideias iniciais para os painéis interativos. Logo após, cada voluntário, conforme sua aptidão, desenvolveu elementos (recortes, desenhos e colagens) para compor os painéis.

A ideia central dos painéis é que, com o decorrer das atividades, o mediador conduza a montagem de forma ilustrativa e interativa. Para tanto, como pode ser visto na Figura 02 , os painéis foram formatados para receber as futuras informações, de acordo com a dinâmica proposta para a oficina. Através de recortes coloridos, frases, palavras de efeito e figuras ilustrativas, os painéis foram divididos em quatro (04) temáticas, cada um com objetivos específicos, a fim de direcionar a discussão para todos os setores que envolvessem direta e indiretamente o desenvolvimento do programa de necessidades.

Figura 02 - Recortes e colagens para montagem dos painéis

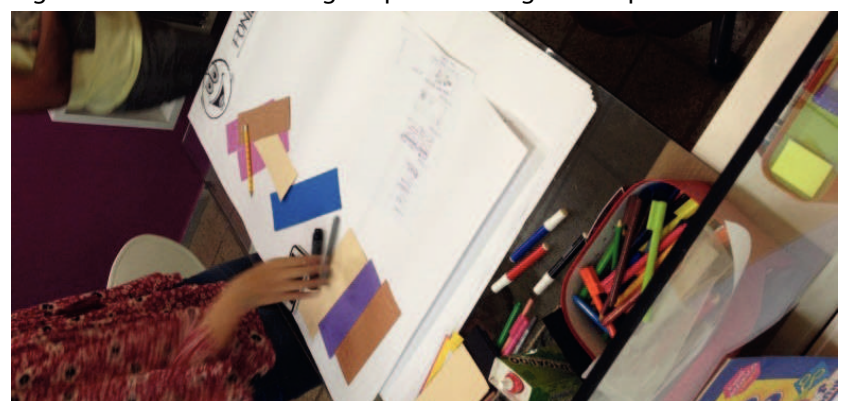

Fonte: Acervo do autor (2015).
A Figura 03 apresenta o material produzido para a oficina, suporte para a discussão e preenchimento coletivo. O primeiro painel, intitulado "união", tem um papel de reforçar os conceitos, a ideia de união e sua importância para o sucesso das atividades desenvolvidas pela associação. O segundo painel organiza, através de figuras representativas os "pontos positivos e negativos" expostos em faixas coloridas inseridas durante a atividade. $O$ terceiro painel ilustra, através de figuras e faixas coloridas informativas, a ordem do processo produtivo, desde a região até o consumidor final. No último painel, a pergunta em destaque - o que você sonha para sua sede? - apresenta a imagem de uma árvore com galhos e ramos vazios. A intenção é que ao longo das discursões sua copa fosse preenchida com faixas coloridas indicando, através de tópicos, os "sonhos e desejos" dos participantes.

Figura 03 - (a) Formatação para o primeiro painel intitulado - "união e associação". (b) Figuras iniciais para o segundo painel - "pontos positivos e negativos". (c) lustrações para o terceiro painel - "da horta à feira". (d) Frases e figuras para o painel - "O que você sonha para nossa sede?"

(A)

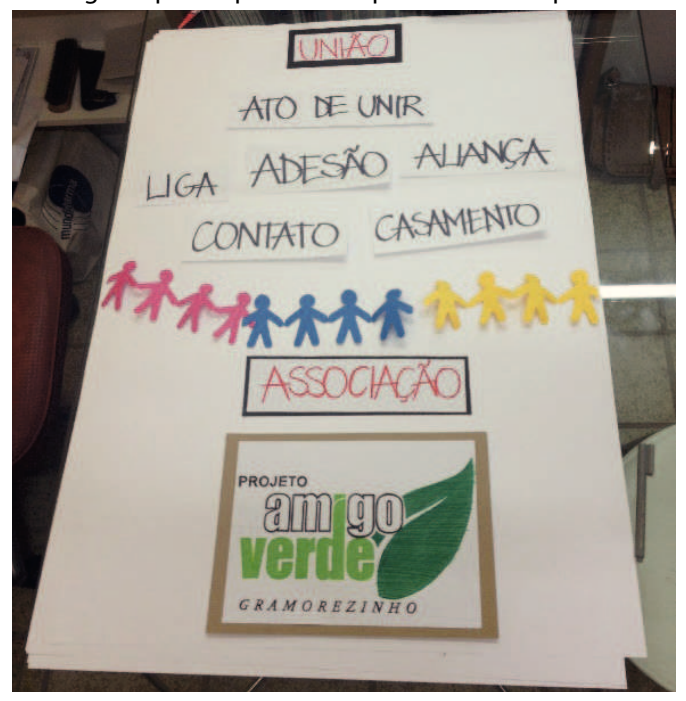

(B)

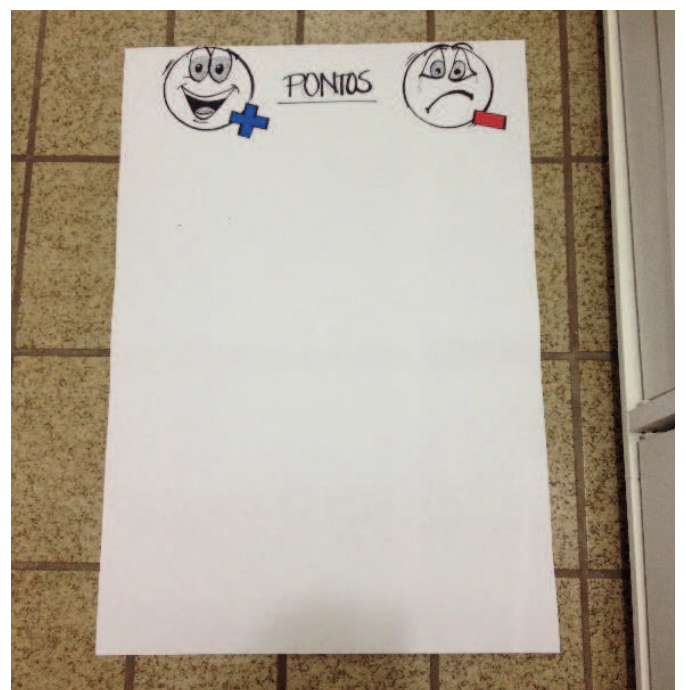


(C)

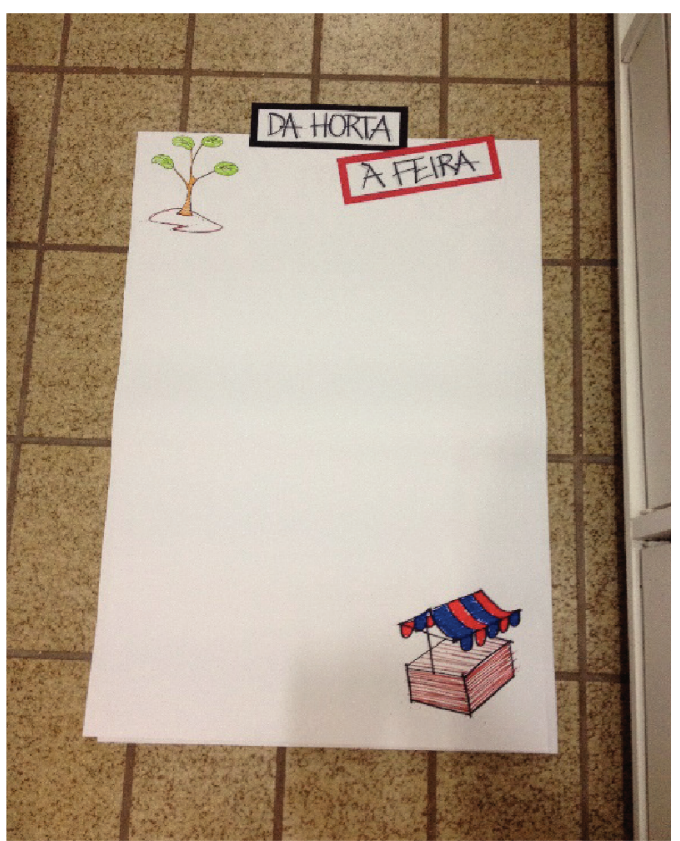

(C)

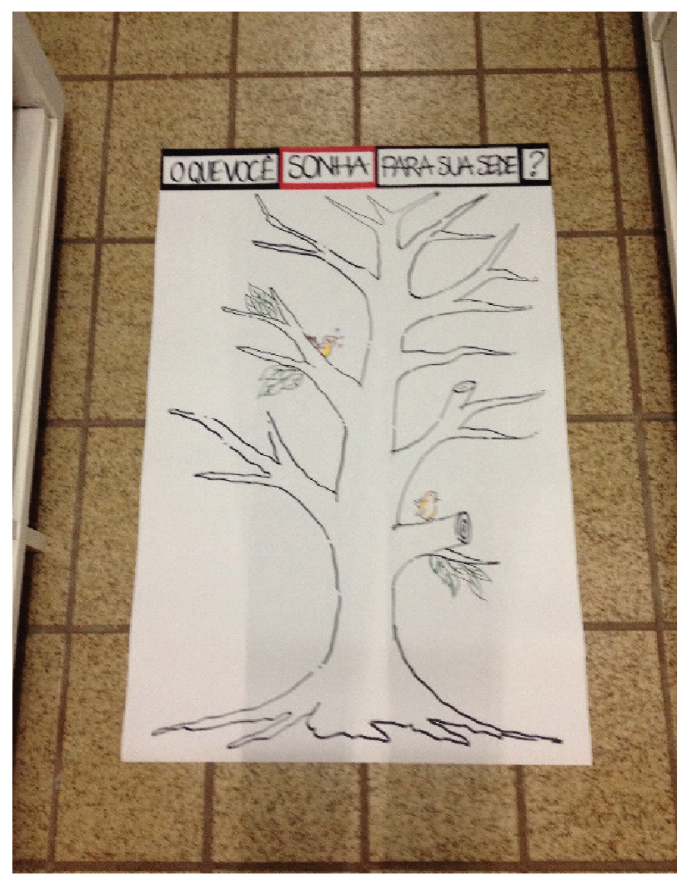

Fonte: Acervo do autor (2015)

E por último a vivência da oficina participativa - o espaço foi preparado para receber os participantes de maneira informal, dispondo cadeiras e os suportes para os painéis de forma circular no ambiente, favorecendo um maior contato visual, como pode ser visto na Figura 04. Após breve apresentação dos participantes (formação acadêmica e instituições envolvidas), procurou-se também, deixar claro o papel do mediador nos momentos dos debates, tendo em vista as contradições entre os problemas apresentados e os objetivos propostos e explorar os conhecimentos não só técnicos, mas os saberes locais.
Figura 04 - Debates iniciais com os associados

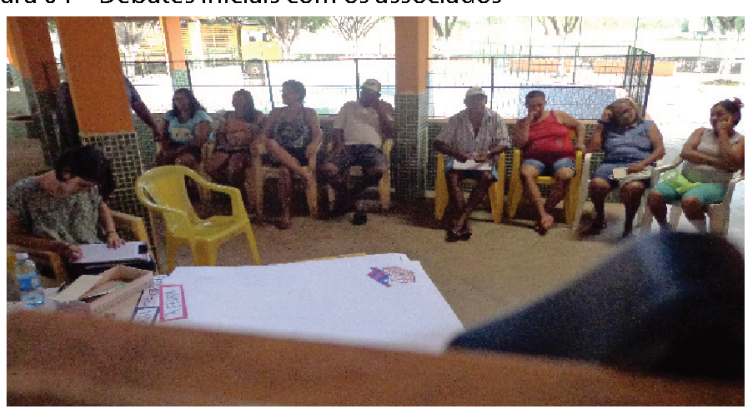

Fonte: Acervo do autor (2015)

\section{RESULTADOS E DISCUSSÕES PARA MONTAGEM DO PROGRAMA ARQUITETÔNICO}

Através dessa atividade foram identificados os desafios e as potencialidades individuais e coletivas, bem como as expectativas em relação ao Centro Comunitário e as necessidades sutis e pragmáticas para a realização do trabalho.

Na montagem do primeiro painel, intitulado "União e Associação" (Figura 05), à medida que o mediador explora a importância da união para o desenvolvimento coletivo, recortes com palavras relacionadas - ato de unir, aliança, liga, adesão, contato, casamento e associação - foram fixados, estimulando os participantes a refletirem sobre a importância da participação e envolvimento de todos para o crescimento do Projeto Amigo Verde.

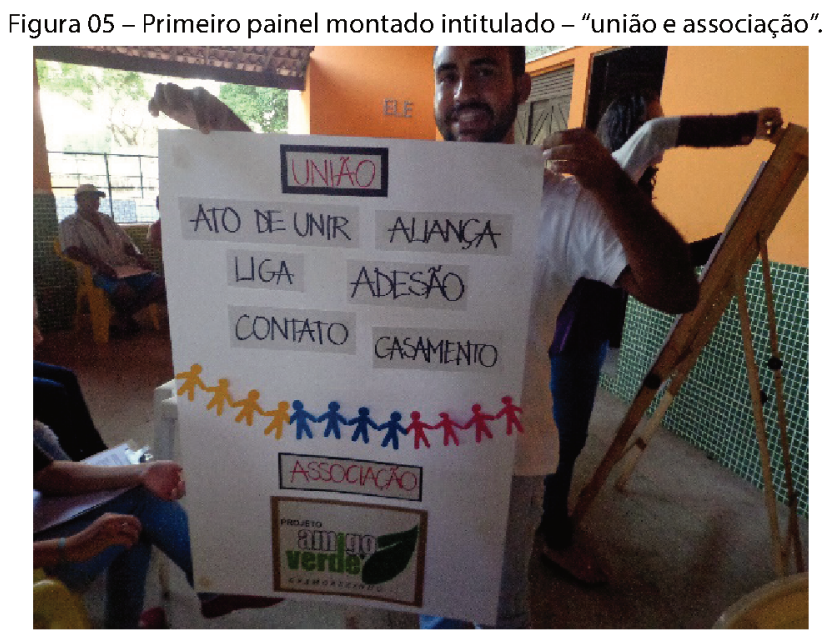

Fonte: Acervo do autor (2015)

O interesse da comunidade se tornou evidente, o Centro Comunitário se configura como uma proposta de fortalecimento. É notório o sentimento de união entre os associados e o senso coletivo é um dos motivos do projeto ter obtido tanta visibilidade, veiculado na mídia não só local como também nacional. A comunidade do Gramorezinho, sob a supervisão do Ministério Público do RN, obteve o reconhecimento da Petrobrás que premia o Projeto Amigo Verde. 
Figura 06 - (a) Segundo painel finalizado. (b) Terceiro painel finalizado.

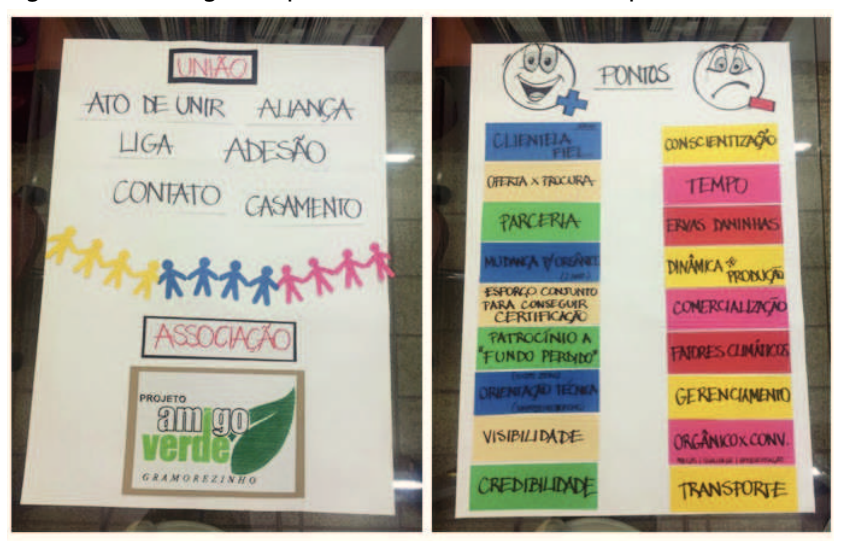

Fonte: Acervo do autor (2015).

Para a formulação de um quadro consistente da atuação do Projeto na atualidade, foi apresentado o segundo painel que propôs explorar os pontos positivos e negativos enfrentados pelos agricultores, dando margem para o surgimento de soluções que possam ser empregadas na proposta arquitetônica. Os resultados podem ser verificados na Figura 06. Destacou-se como ponto positivo: a transição da agricultura convencional para a agricultura orgânica em menos de dois anos, as parcerias com órgãos públicos do Estado, SEBRAE e Petrobrás, que financiaram e capacitaram nesse processo de transição. Entretanto, os moradores ainda enfrentam problemas, mesmo com o sucesso alcançado sofrem com a falta de conscientização da população e planejamento de um local especifico para a feira, abrigado das intempéries. Precisam controlar ervas daninhas sem o uso de agrotóxicos, gerenciar a produção, qualificar os produtores, rapidez para o transporte dos produtos e, o principal, a falta de uma sede. Conclui-se que com a construção do novo edifício, muitos desses pontos negativos podem ser solucionados.

Na Figura 06 também pode ser visto o resultado da discussão que objetivou entender o funcionamento da produção orgânica e o que poderia ser feito na proposta arquitetônica para otimizar essa produção. O terceiro painel, intitulado "Da horta à feira", foi montado em conjunto com os produtores, resultando em uma explanação simples da trajetória do produto desde a colheita até a venda.

Os processos destacados nos levam a entender mais facilmente suas demandas. A higienização, embalagem e estocagem, por exemplo, requerem locais e equipamentos específicos ainda não existentes. O transporte ocorre hoje com o carro da própria associação, porém sem um estacionamento próprio. A montagem e comercialização acontecem com o uso de uma estrutura desmontável (barraca em madeira) que atualmente fica armazenada no depósito do clube "Society Ouro Verde".
A Figura 07 apresenta o último painel, intitulado "O que você sonha para nossa sede?, que explora de forma ampla e livre as intenções dos associados. Para os participantes, a sede representa a ideia de um lugar onde seriam desenvolvidas várias atividades: reuniões, palestras e cursos, além de alguns benefícios: enfermaria, cozinha didática, lazer e aulas de informática. Assim, foi possível notar que outros equipamentos podem ser inseridos no programa de necessidades do edifício, como forma de prover uma maior apropriação do espaço e integração entre os associados e a população local.

Figura 07 - Último painel interativo finalizado
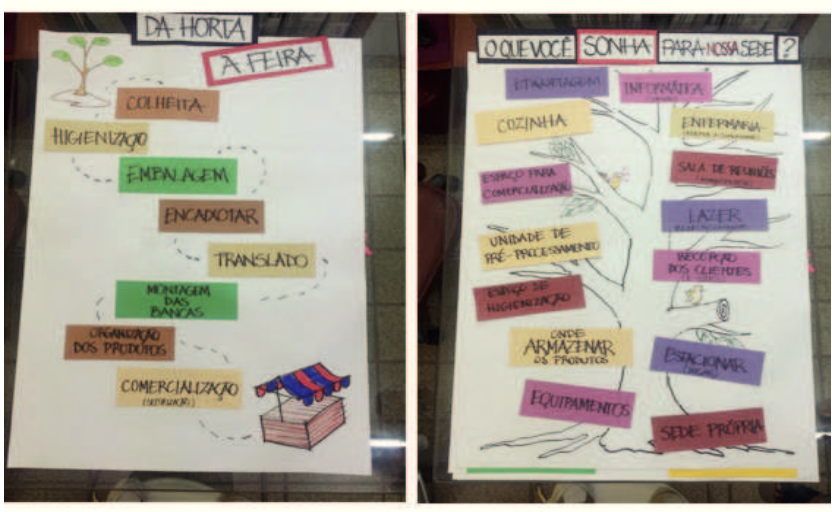

Fonte: Acervo do autor (2015)

Compreende-se que as discussões e os painéis ilustrativos finais, proporcionaram um intercâmbio de conhecimentos e um amadurecimento para o grupo envolvido, percebendo-se entusiasmo entre produtores e também um registro do saber popular acerca dos temas tratados. Assegura-se, dessa forma, um processo de construção coletivo da proposta arquitetônica. Ressalva-se que este é um projeto participativo em parte, uma vez que o processo criativo do novo edifício não será discutido com a comunidade. Isso se dá pelo limite de tempo do projeto, não permitindo que seja feito um trabalho plenamente coletivo e contínuo.

O processo participativo de projeto, mais completo que o tradicional, demanda maior quantidade de tempo e, por isso, nem sempre é passível de ser aplicado. Concursos, ou outros casos que exijam um curto prazo de apresentação, por exemplo, estariam, quase sempre, eliminados desse procedimento, assim como situações que envolvam dificuldades de compreensão de escala do projeto etc. (PRONSATO, 2005, p. 126).

Mesmo assim, a Oficina Participativa se mostrou uma importante ferramenta para compreensão das principais necessidades, sob o olhar do produtor A participação da comunidade 
foi fundamental para perceber determinadas características técnicas da produção orgânica, ainda pouco compreendida.

Como resultado desse processo participativo com os agentes que estarão presentes durante o uso, operação e manutenção da edificação, sempre em concordância com os aspectos da sustentabilidade e eficiência energética, foram criados dois núcleos de atividades com ambientes e funções específicas, que podem se comunicar visualmente ou fisicamente para garantir maior interatividade aos espaços. São eles:

O núcleo de integração social, que agrega ambientes voltados para social e também destinados a acolher atividades culturais e/ou recreativas.

O núcleo de beneficiamento orgânico, que tem como função atender especificamente as dinâmicas de beneficiamento da produção orgânica dos agricultores vinculados ao projeto Amigo Verde, contemplando atividades complementares como a horta educativa (voltada para o treinamento e ações pedagógicas) e a feirinha orgânica, que acontecerá no próprio terreno. Também visa atender as necessidades de mobilidade dos funcionários, fornecedores e visitantes.

\section{CONSIDERAÇÕES}

Por fim, aliando a experiência participativa aos princípios da arquitetura bioclimática, foi possível ainda a construção de um painel conceitual fruto dessa vivência com os moradores e com o lugar. O painel apresentado na Figura 08 contém desenhos e palavras que expressam a relação dos usuários com a agricultura; a terra, o "mato" e possíveis desejos que podem ser vivenciados no centro comunitário. Explorou-se ainda, a ideia dos espaços livres e conectados com a natureza, a criação de conjuntos de equipamentos que possam desenvolver e acolher atividades de integração social e recreativas de forma orgânica e simples.

Figura 08 - Painel conceitual

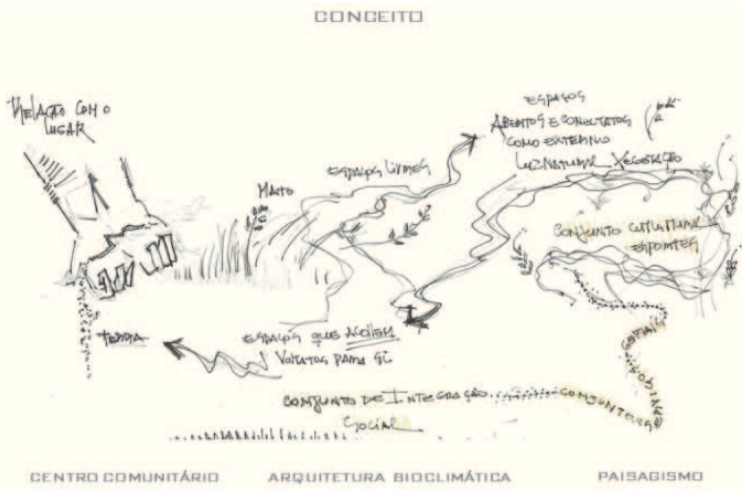

Fonte: Elaborado pelo autor (2015).
Em seguida, houve a necessidade de criar outro painel (Figura 09) utilizando imagens e palavras-chave que representassem os temas centrais para o projeto. Dividido em três "setores", o primeiro vinculado ao sentimento de pertencimento (tipicidade) com a terra e as atividades a ela ligadas, o segundo reforça o ato de dialogar (fluidez) do edifício com as áreas externas, utilizando princípios bioclimáticos para criar uma arquitetura vinculada com os elementos naturais. Enfim, o aspecto do sentir como ponte entre a arquitetura e a paisagem, com o intuito de explorar elementos sensoriais que o paisagismo pode proporcionar nos espaços criados pelo homem.

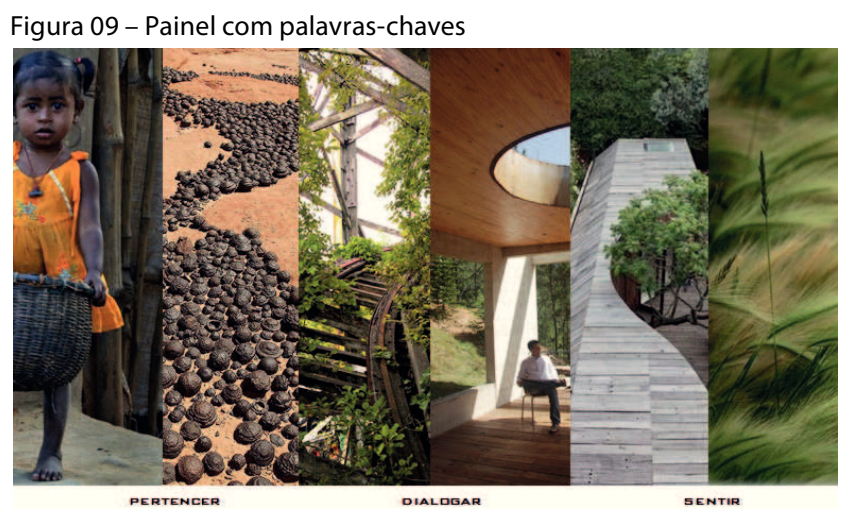

Fonte: imagens retiradas do Pinterest e editadas pelo autor (2015).

Diante dos painéis elaborados, na tentativa de representar e sintetizar conceitualmente as intenções da proposta, foi possível apresentar uma única imagem e frase conceitual. A imagem (Figura 10) reanima o valor das sensações da memória afetiva vinculada aos elementos naturais, que é intensificada pela frase "arquitetura com cheiro de mato" e também reforça o argumento sensorial, afetivo e sustentável para o estudo.

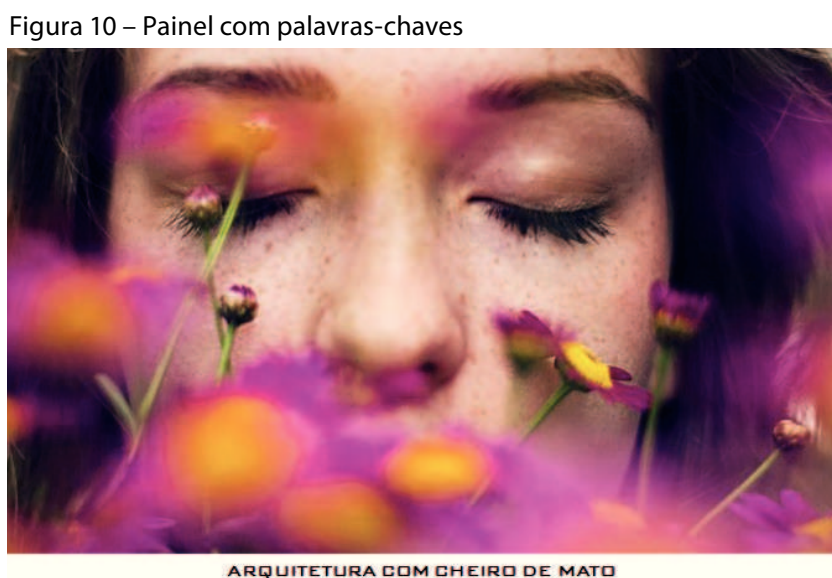

Fonte: imagens retiradas do Pinterest e editadas pelo autor (2015). 
A partir da experiência junto à comunidade e levando em consideração os aspectos cênico-paisagísticos da região, percebeu-se que o Centro Comunitário poderá contribuir como instrumento de fortalecimento dos laços sociais e compartilhamento de experiências através de espaços físicos integradores rodeados de jardins, que valorizem a vegetação nativa e favoreçam o diálogo entre o edifício e a singular paisagem local.

Nesse processo também foi importante compreender os principais condicionantes projetuais para o desenvolvimento da proposta, como: o lugar, sua ocupação, aspectos morfológicos e bioclimáticos, tecnologias e técnicas construtivas empregadas, os instrumentos legais e aspectos culturais e econômicos dos usuários, a fim de estabelecer princípios fundamentais para a definição da proposta.

A experiência com a oficina participativa feita com os moradores e associados que, além de proporcionar uma maior proximidade com a realidade da região, contribuiu para o entendimento dos processos de beneficiamento e das aspirações e carências da comunidade. Ambos, de suma importância para concepção de um programa de necessidades eficiente e coerente com o lugar.

"Arquitetura com Cheiro de Mato", como conceito da proposta, surge da reunião destas experiências com os materiais e a vegetação estudados, conteúdos apreendidos durante o mestrado, conversas com professores e orientadores; além disso, a paisagem, as impressões e sensações vividas no local, integrando o lado subjetivo e autoral do projeto.

O trabalho ressalta a importância de incorporar estratégias bioclimáticas e participativas ao projeto arquitetônico, no processo de concepção, como forma de garantir resultados integrados aos valores ambientais e da comunidade. Isto, possivelmente, poderá servir, não só como um elemento de fortalecimento à autoestima da comunidade local, mas também como referência para novas ações na cidade.

\section{REFERÊNCIAS}

AMARAL, I. Ressaltando as tensões tectônicas: a complexidade dos conflitos criativos e construtivos na concepção do projeto. ENANPARQ II Encontro Nacional de Pesquisa e Pós-Graduação em Arquitetura e Urbanismo. Natal: [s.n.]. 2012.

ASBEA. Guia sustentabilidade na arquitetura: diretrizes de escopo para projetistas e contratantes. São Paulo: Prata Design, 2012.
BITTENCOURT, L.; CÂNDIDO, C. Ventilaçao Natural em Edificações. PROCEL EDIFICA. Rio Janeiro. 2010.

BONFIM, C. D. J. et al. Centro Comunitário. Núcleo de Documentação Técnica e Divulgação. Lisboa PT. 2000.

CAPISTRANO, L. F. D. et al. Memória minha comunidade: Lagoa Azul. Secretaria Municipal de Meio Ambiente e Urbanismo- SEMURB. Natal. 2013.

CORBELLA, O.; YANNAS, S. Em busca de uma arquitetura sustentável para os trópicos: conforto ambiental. Rio de Janeiro: Revan, 2003.

CORREA, C. B. DROPS. www.vitruvius.com.br, 2001. ISSN 004.07. Disponivel em: <http://www.vitruvius.com.br/revistas/read/drops/02.004/1590>. Acesso em: 17 jul. 2015

HOLANDA, A. D. Roteiro para construir no nordeste: arquitetura como lugar ameno nos trópicos ensolarados. Recife: UFPE Mestrado de Desenvolvimento Urbano, 1976.

LAWSON, B. Como arquitetos e designers pensam. 1. ed. São Paulo: Oficina de textos, 2011.

MAHFUZ, E. D. C. Ensaio sobre a razão compositiva: uma investigação sobre a natureza das relações entre as partes e o todo na composição arquitetônica. Belo Horizonte: AP Cultural, 1995.

NUNES, D. Pedagogia da participação. Salvador: UNESCO/Quarteto, 2002.

PRONSATO, S. A. D. Arquitetura e Paisagem: projeto participativo e criação coletiva. 1. ed. São Paulo: AnnaBlume, Fapesp, Fupam, 2005.

\section{AGRADECIMENTOS}

Aos produtores e associados do projeto Amigo Verde pela disponibilidade na oficina participativa, como também, pela grande contribuição na elaboração do programa arquitetônico deste trabalho.

Aos colegas e alunos pelo apoio no desenvolvimento dessa etapa fundamental do projeto. 